\title{
The new Italian law 219/2017: an extraordinary clinical tool in internal medicine
}

\author{
Matteo Bolcato, Giacomo Fassina, Matteo Sanavio, Anna Aprile \\ Department of Molecular Medicine, Legal Medicine, University of Padua, Padua, Italy
}

\begin{abstract}
In December 2017, Law 219 named 'Provisions for informed consent and advance treatment directives' was approved in Italy, and on the one hand, this law helped the daily medical activity, and on the other hand, it enhanced the patient's self-determination. This contribution analyzes the new legislative disposition and the possible medical-legal and practical implications for patients entrusted in hospitals. In particular, it focuses on the usefulness of early planning of medical care decisions in complex pathological situations in order to enhance the patient's self-determination and his eventual impassable refusal. It also safeguards the medical work from disputes and claims, preserving medical autonomy and competence.
\end{abstract}

\section{Introduction}

On $22^{\text {nd }}$ December 2017, the Law no. 219/2017 'Provisions for informed consent and advance treatment directives', ${ }^{1,2}$ comes after a long political and cultural discussion, especially regarding the possibility of refusing potentially life-saving health treatments. It also gives the possibility to anticipate the clinical decision about treatments and procedures in the anticipation of a pathological situation that potentially makes the patient unable to decide. With this intervention, the risk of implementing a persistent therapy or incongruous assistance is lowered. ${ }^{3-6}$

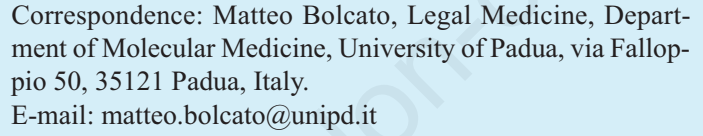
ment of Molecular Medicine, University of Padua, via Falloppio 50, 35121 Padua, Italy.

E-mail: matteo.bolcato@unipd.it

Key words: Informed consent; patients' self-determination; shared care planning; advance directives.

Contributions: all authors contributed equally.

Conflict of interests: the authors declare no potential conflict of interests.

Ethics approval: not required.

Received for publication: 26 March 2020.

Revision received: 21 April 2020.

Accepted for publication: 21 April 2020.

This work is licensed under a Creative Commons Attribution NonCommercial 4.0 License (CC BY-NC 4.0).

${ }^{\circ}$ Copyright: the Author(s), 2020

Licensee PAGEPress, Italy

Italian Journal of Medicine 2020; 14:184-188

doi:10.4081/itjm.2020.1280
The law is structured in eight articles and in particular: i) clear indications for informed consent: the terms of the information that has to be given to the patient, the possible forms of expression of consent, the usefulness of the patient's will regarding the unwanted health treatments, indications regarding hydration and artificial nutrition, professional medical liability implications concerning the refuse of a medical act or therapies; ii) indications about access to pain therapy and dignity in the final stage of life; iii) the possibility of giving consent or dissent to medical acts and treatments before the occurrence of pathologies, that could lead to a loss of autonomy, through a) the anticipated provisions of treatment and $b$ ) the joint planning of treatments.

In this paper, we want to analyze these elements in order to make them practical for clinical use in daily medical activity.

\section{Informed consent and refusal}

Art. 1 paragraph 2 and 3: Care relationship and trust between patient and doctor are promoted and valued; the informed consent is expressed considering the patient's decision-making autonomy and competence, the professional medical autonomy, and the doctor's responsibility. (...) Each person has the right to know their health conditions and to be informed in a complete, updated and understandable way regarding the diagnosis, prognosis, benefits, and risks of the diagnostic tests and indicated health treatments, as well as regarding possible alternatives and the consequences of any refusal of the medical treatment or the diagnostic assessment (...). Article 1 focuses on determining the discipline of informed consent. Far from being a simple formal paper act, it becomes the true expression of the patient's decision-making autonomy, affirming that no act can be started or continued with- 
out the patient's consent. With this Law, a real empathic relationship and continuous process of dialogue between patients and doctors, become the fundamental base of the medical care alliance. This relationship is based on information that, by law, becomes the patient's right and qualified as complete and updated concerning all activities.

Paragraph 2 enhances and promotes the care relationship between doctor and patient. It has not to be a one-sided flow of data, but it has to have at the base the patient's decision-making autonomy interacting synergistically with the competence, responsibility, and professional autonomy of the doctor. The latter prevents the risk for the professional to be forced to bend his/her skills to the patient's requests when these conflict with his/her clinical conviction. The doctor can thus legitimately refuse a treatment requested by the patient if it is inappropriate in light of the scientific knowledge available and the clinical presentation of the patient. Consequently, exercising not only a right but a duty of its own. In this sense, the professional autonomy of the doctor acts as a counterweight to the principle of informed consent, consequently safeguarding the mutual spaces of freedom. The concept of relationship care extends, in paragraph 2 , to the entire healthcare team on one side and, on the other side, to the patient's relatives, if the patient wishes, emphasizing the importance of the circle of affections and relationships that surrounds the individual.

Paragraph 3 outlines the breadth of information to be provided to the patient, which must be not only complete but also adequate for the patient's ability to understand and rendered in a balanced, truthful and responsible manner so that he can effectively and conscientiously express his will; in this sense, the processing and the transmission of information are as important as the information itself. However, the person has no obligation to be informed, being able to refuse health information; this refusal must be explicit and carefully recorded in the patient chart. Then, the patient may indicate family members or a person of his trust as those in charge of receiving the information and expressing consent in his place. The legislation also regulates the form of documentation.

Paragraph 4 illustrates, in fact, the duty and the various possibilities of documenting the consent/dissent, without introducing the excessive obligation of the written form for each type of consent, except for the few and specific cases in which the written form is provided for by law (e.g., blood or blood's components transfusion, donation of blood and marrow, HIV diagnostic assessment, donation of organs/tissues, removal and grafting of the cornea, rectification regarding attribution of sex, clinical experimentation, etc.)

Another important contribution derives from the concrete definition of respect within the doctor-patient relationship. Pursuant to paragraph 5, the patient capable of self-determination has the right to refuse, in whole or in part, any diagnostic assessment or health treatment, as well as the right to revoke the consent given at any time, even when the revocation involves the interruption of the treatment itself. The law explicitly recognizes artificial nutrition and artificial hydration as health treatment as they are administered on medical prescription through medical devices; this aims to definitively resolve the ethical and bio-juridical debate following the Englaro case. ${ }^{7}$ In light of these statements, the physician has the possibility not to initiate medical acts that the patient refuses but also to interrupt them eventually. Regarding these issues, before this law and in an era characterized by the presence of an important legal-medical dispute ${ }^{8-12}$ some circumstances and decisions related with a refusal of the patient may raise concerning for professional medical liability claims. ${ }^{13-16}$

Paragraph 6 clarifies the issue and establishes that the doctor - and with him, all the healthcare team - is required to respect the patient's willingness to refuse/renounce health treatment and is exempted from civil or criminal liability when he respects these wills. On the other hand, the doctor is not required to implement health treatments requested by the patient, which are, however, contrary to the law, professional ethics, or good clinical-care practices, towards which he has no professional obligations.

Discretionary spaces are opened, however, in emergencies such as in paragraph 7, where it is imperative to comply with the patient's wishes in any case if the clinical conditions and circumstances allow to receive them.

Paragraph 8 is totally and exclusively used to affirm the cardinal principle of law 219/2017: the time of communication between doctor and patient constitutes healthcare time. This affirmation completes with sobriety the provisions of the preceding paragraphs and constitutes a strong statement for the entire profession, which must know how to mediate and commit itself to know the context in which it operates, finding the time and space to build the relationship of care.

Paragraph 9 is directed to public and private healthcare structures, which must guarantee the correct application of the principles preserved in the law with the implementation of their organizational methods.

Paragraph 10 highlights the need to take care of communication methods to redesign the care relationship between doctor and patient effectively; this objective must also be pursued through the continuous training of health professionals. The legislative provision also recognizes the possibility of indicating, in advance, the patient'swill regarding health choices through specific instruments such as advance treatment provisions and the joint planning of treatments. 


\section{The advance provisions of treatment}

Art. 4, paragraph 1. Any person of legal age and capable of understanding and wanting, in prevision of any future inability to determine themselves and after having acquired adequate medical information on the consequences of their choices, can, through the APT, express their own will in the matter of health treatments, as well as consent or refusal with respect to diagnostic tests or therapeutic choices and individual health treatments. It also indicates a trusted person who takes his place and represents him in the relations with the doctor and with the healthcare facilities.

Article 4 defines a completely new legal instrument with which healthcare professionals will necessarily have to face in clinical practice: the anticipated provisions of treatment (APT).

In paragraph 1 the APT find their regulatory definition; they are the real expression, in a legal act or biological testament, of the person who, at the time of drafting, could be in perfect health but wants to express his will in the matter of health treatments, as well as the consent or refusal regarding diagnostic exams, therapeutic choices or individual health treatments, with which the doctor is required to comply.

The role of the trustee, whose definition is completed in the following paragraphs 2,3 , and 4 , is defined as an adult, with full possession of his or her faculties to take the place of the patient and to represent him in the relations with doctors and with healthcare facilities. The nomination of the trustee constitutes a possible, and not essential content of the APT: the law expressly admits the possibility not to nominate a trustee; it also provides for the hypotheses of revocation or renunciation of the assignment, without subordinating them to the indication of a new person with these functions. The legislation does not even prohibit the nomination of multiple trustees, but it is generally recognized the opportunity to identify one of them only to avoid possible situations of conflict between them.

In paragraph 5, it is stated that the APT can be disregarded accordingly with the trustee. This clearly explains not only the natural possibility of the subjects to change their beliefs but also future improvements of medical science, not computable at the time of the stipulation of the APT, as well as the possible, obvious inconsistency or lack of correlation with the current clinical situation. Considering the possibility of a conflict between the trustee and the doctor, the decision, in this case, is left to the judge, according to paragraph 5 of article 3 .

In paragraph 6, there is the greater rigidity of the APT in its formulation. Despite the informed consent, the APT must be drawn up by public deed, by authenticated private writing or by private writing personally delivered by the settlor to the registry office of the mu- nicipality of residence, which provides for the annotation in a special register. In the event that the physical condition of the patient does not allow it, the APT can be expressed through video recording or devices that allow the person with disabilities to communicate. With the same forms, they are renewable, modifiable, and revocable at any time.

Pursuant to Ministerial Decree of $10^{\text {th }}$ December 2019 , no. 168 , regarding the regulation concerning the national database destined to the registration of the APT, it has been founded a computed database to register the APT, which can be consulted by any hospital in the national territory.

\section{Shared care planning of treatments}

Art. 5 paragraph 1: In the relationship between patient and doctor referred to in article 1, paragraph 2, regarding the evolution and the consequences of a chronic and disabling pathology or characterized by unstoppable evolution with a poor prognosis, the healthcare team can establish a joint planning of the care shared between the patient and the doctor, with which the doctor and the health team are required to comply if the patient finds himself in a position where he cannot express his consent or in a condition of incapacity.

Article 5 defines the shared care planning (SCP), a crucial tool for pursuing the purpose of personalized medicine, focusing the doctor's attention on the needs of the individual patient. The SCP appears to be a different tool from the APT: although they are both a vehicle for self-determination of the individual, the APT refer to health treatments and see the person as the primary subject of the action, while the $\mathrm{SCP}$, is an instrument with greater precision and concreteness, places common decision of healthcare acts at the center and involves a process that develops the relationship between doctor and individual, who has already become patient, and that is experiencing a pathological situation. Regarding the beneficiary of the SCP, the interpretation of legislation places the principle of treatment planning at the disposal of patients capable of acting. At the beginning of the first paragraph, it is made clear that the SCP is about the evolution of the consequences of a chronic and disabling pathology or characterized by unstoppable evolution with a poor prognosis. The two conditions described, however, could lead to multiple interpretations, the chronic pathology referring to multiple degrees of disability or the poor prognosis to the quality of life, the duration of the disease, or even death. Therefore, it is possible to create an SCP in any case of pathology and without particular time constraints; regarding this, there is the possibility of updating the $\mathrm{SCP}$ as the disease progresses. The $\mathrm{SCP}$ is a powerful instrument, where the doctor offers the 
patient his/her technical-scientific competence making sure that it is well understood: the doctor will then have to accept the patient's choice, the result of a complete and fully informed communication and decision-making process. Concerning the information, it must be general, regarding the patient's health conditions, and in particular on the possible evolution of the pathology in progress, on what the patient can realistically expect in terms of quality of life, on clinical possibilities to intervene, and on palliative care. Article 5 also provides for the specific figure of the trustee who has the role of representing the patient and managing the situations in which the clinical conditions contemplated in the SCP occur, and informing the professionals who did not take part to the planning process about this document. In addition, he will explain and represent the patient whenever the content of the SCP is unclear or ambiguous; the trustee will then be able to suggest its appropriate interpretation through his knowledge of the patient's life conception and aspirations. From these considerations, therefore, derives the opportunity for the trustee to attend the drafting of the SCP document, where the patient will be able to explain the role entrusted to the trustee in a detailed and modeled manner based on his needs. Regarding the powers attributed to the trustee, the patient can confer a merely attesting function (confirming the patient's will with a path already completely outlined), or integrative (departing or integrating the schedule in the presence of specific circumstances) or completely creative (the possibility of making decisions by replacing the patient). Given the elusiveness of the normative text on the matter and the risk of interpretative doubts on the extent of the trustee's powers, with significant consequences on the clinical-therapeutic choices, it is highly recommended to carefully take care of the definition phase of the SCP, diligently specifying the role that the patient intends to attribute to the appointed trustee. In case of decisions made by the trustee that are not shared with the patient and/or manifestly inconsistent with and/or not respectful of the patient's interest, the doctor, finding himself in conflict, must proceed by requesting the intervention of a judge, according to paragraph 5 of article 3 .

Formulating an SCP involves an informative preliminary phase, a phase of evaluation between the indications provided by the doctor and the aspirations of the patient, then, in the last part, the agreement between the professional and the patient with the involvement of the trustee. This process must be fully confirmed in a special report, signed by all parties involved, which must be included in the patient's medical record and electronic health record, having the same legal value. It is also advisable to provide a copy of the report to the patient himself and the appointed trustee.

\section{Conclusions}

In modern medical practice, it is useful to have a legislative provision inherent the informed consent, which clearly delineates opportunities and limits of medical activities performed on the person. The law is an exceptional tool for real personalized medicine by focusing attention on the needs of the individual patient and, at the same time, decreasing the risk of professional medical liability. The SCP, in particular, tries to put the decision-making interlocutors on the same level by pursuing intermediation or, in any case, a comparison, in order to safeguard the patient's health and life conditions, in an adequate and qualified information context. Up to the present time, there is a sort of inertia in the complete application of the legislative provisions. Therefore, further efforts must be made to render it an ordinary practice for both the healthcare professionals and citizens.

\section{References}

1. Di Paolo M, Gori F, Papi L, Turillazzi E. A review and analysis of new Italian law 219/2017: 'provisions for informed consent and advance directives treatment'. BMC Med Ethics 2019;20:17.

2. Di Luca A, del Rio A, Bosco M, di Luca NM. Law on advance health care directives: a medical perspective. Clin Ter 2018;169:e77-81.

3. Solarino B, Bruno F, Frati G, et al. A national survey of Italian physicians' attitudes towards end-of-life decisions following the death of Eluana Englaro. Intensive Care Med 2011;37:542-9.

4. Rubulotta F, Rubulotta G, Santonocito C, et al. End-oflife care is still a challenge for Italy. Minerva Anestesiol 2010;76:203-8.

5. Gristina GR, De Gaudio R, Mazzon D, Curtis JR. End of life care in Italian intensive care units: where are we now? Minerva Anestesiol 2011;77:911-20.

6. La Russa R, Viola RC, Di Fazio N, et al. Consenso informato e APT (disposizioni anticipate di trattamento): momento legislativo innovativo nella storia del biodiritto in Italia. Respons Civile Previd 2018;1: 353-66

7. Moreschi C, Da Broi U, Rodriguez D, et al. The Eluana Englaro Case: cause of death after the withdrawal of artificial nutrition and hydration in a subject in a permanent vegetative state and with quadriplegia. Forensic Sci Int 2013;231:e24-9.

8. Bolcato M, Russo M, Donadello D, et al. Disabling outcome after peripheral vascular catheter insertion in a newborn patient: a case of medical liability? Am J Case Rep 2017;18:1126-9.

9. Bolcato M, Aprile A, Caenazzo L, et al. An unusual case of chronic cough: Professional liability in dentistry? Respir Med Case Rep 2016;19:190-2.

10. Tozzo P, Caenazzo L, Rodriguez D, et al. Delayed diagnosis of wernicke encephalopathy with irreversible neural damage after subtotal gastrectomy for gastric cancer: 
a case of medical liability? Int J Surg Case Rep 2017;30:76-80.

11. Bolcato M, Fassina G, Rodriguez D, et al. The contribution of legal medicine in clinical risk management. BMC Health Serv Res 2019;19:85.

12. Russo M, Bolcato M, Sabadin V, Aprile A. The medicolegal assessment of aesthetic damage. A correlation analysis between experts and an operative proposal. Leg Med (Tokyo) 2019;40:47-53.

13. Bolcato M, Russo M, Aprile A. La nuova legge sulla responsabilità professionale: Cosa cambia in punto di linee guida? Quaderni ACP 2017;24:263-7.
14. Aprile A, Bolcato M, Fabbri LD, Rodriguez D. Proposta di un indicatore di qualità nella valutazione medicolegale della responsabilità professionale in ambito sanitario. Riv It Med Leg 2014;36:1180-1178.

15. Marchetti D, Sgarbi I, Feola A, et al. Il risarcimento della violazione del consenso informato nella giurisprudenza del Tribunale Civile di Roma (Anni 2012-2016). Riv It Med Leg 2019;41:601-19.

16. Casonato C. Taking sick rights seriously: la pianificazione delle cure come paradigma di tutela delle persone malate. Riv It Med Leg 2018;3:949-963. 